Original Research Paper

\title{
A Reliable Method of Analysis for Geotechnical Data
}

\author{
${ }^{1}$ Abdolrasoul Ranjbaran, ${ }^{2}$ Mohammad Ranjbaran and ${ }^{3}$ Fatema Ranjbaran \\ ${ }^{1}$ Department of Civil and Environmental Engineering, Shiraz University, Shiraz, Iran \\ ${ }^{2}$ Department of Chemical Engineering, Yasuj University, Yasuj, Iran \\ ${ }^{3}$ Department of Mechanical Engineering, Shiraz University, Shiraz, Iran
}

\begin{abstract}
Article history
Received: 04-11-2020

Revised: 21-12-2020

Accepted: 26-12-2020

Corresponding Author:

Abdolrasoul Ranjbaran

Department of Civil and

Environmental Engineering,

Shiraz University, Shiraz, Iran

Email: ranjbarn@shirazu.ac.ir: aranjbaran@yahoo.com
\end{abstract}

\begin{abstract}
Geotechnical engineering is the art of making decisions in the presence of uncertainty, where real world problems are treated and this is associated with uncertainties arising from various sources. The sources of uncertainty may be divided into uncertainties of nature and uncertainties of mind. The uncertainties of nature are due to variation of encountered phenomena, e.g., the shear strength in a soil. This is reduced by obtaining more reliable data via the results of tests. The uncertainties of mind are related to the modelling, which may be reduced by change of philosophy. Here, the data is considered as variable instead of random so is reliable. Based on logical reasoning and concise mathematics a reliable formulation, i.e., the change of state philosophy which is digested in the Persian curve is proposed. The Persian curve method is free of uncertainties of mind. In the presented paper the Persian curve method is used to manage the variable geotechnical data in a form that can easily be used in practical geotechnical work for decision making and design.
\end{abstract}

Keywords: Geotechnical Data, Change of State Philosophy, Persian Curve, State Functions, Aleatory Uncertainty, Epistemic Uncertainty

\section{Introduction}

Geotechnical engineering is the art of making decisions in the presence of uncertainty. Within this field, real world problems are treated and this is associated with uncertainties arising from various sources. The sources of uncertainty may be divided into uncertainties of nature (aleatory) and uncertainties of mind (epistemic). The uncertainties of nature are due to variation of encountered phenomena, e.g., the shear strength in a soil. This is reduced by obtaining more reliable data via the results of tests. Some of the pioneers in the field of geotechnical engineering, such as Karl Terzaghi, Arthur Casagrande and Ralph Peck, recognized that it was not always feasible to take fully into account all the uncertainties involved in design. Instead they proposed a structured methodology where the evaluation of the probability conditions of quantities involved in design were supplemented by evaluations based on possible unfavorable deviations from these conditions. They called it the experimental or observational method (Peck, 1969; Christian, 2004; Ang and Tang, 2007). Application of probabilistic methods in geotechnical engineering has been increased in recent years. According to (El-Ramly et al., 2002), probabilistic slope stability analysis was one of the first application of reliability-based design in geotechnical engineering and dated back to the 1970. Since then, a lot of work has been put into the uncertainty in soil properties (Lumb, 1974; Orchant et al., 1987; Phoon and Kulhawy, 1999) and the development of probabilistic calculation algorithms (Griffiths and Fenton, 2004; Xu and Low, 2006). Some published papers on the subject of characterization of the geotechnical properties and the stability analysis are in (Zhang et al., 2004; 2009; 2010; Cao and Wang, 2013; Ching et al., 2010; Wu, 2011). Variability and uncertainty associated with natural variation of properties and inaccuracy caused by lack of information on parameters of models led the field of geotechnical engineering to be an active area of study in the last decade (Müller, 2013; Li, 2014; Johari et al., 2015; Johari and Khodaparast, 2015; Allahverdizadeh Sheykhloo, 2015; Maknoon, 2016; Wolebo, 2016; Das, 2016; Ersöz, 2017; Hernvall, 2017; Kanwar, 2018; Singh, 2018; Aladejare and Wang, 2018; Johari and Mousavi, 2019; Obregon and Mitri, 2019; Masoudian et al., 2019; Johari et al., 2020; Tran, 2019). A close insight into the aforementioned and other literature, led the authors to detect a need for further research and remedy. Toward the aim an intensive and extensive research is conducted in the past 20+ years. The result of investigations of Author's Research Team (ART) concluded in a new 
perspective of the knowledge, the so called Change of State Philosophy (CSP) which is digested in the Persian Curve (PC), where a phenomenon is defined as change in the system (Ranjbaran et al., 2008; Ranjbaran, 2010; Ranjbaran et al., 2011; Ranjbaran, 2012a; 2012b; Ranjbaran, 2013; Ranjbaran and Rousta, 2013a; 2013b; Ranjbaran et al., 2013a; 2013b; Ranjbaran and Ranjbaran, 2014; Ranjbaran, 2014; 2015; 2016; Ranjbaran and Ranjbaran, 2016; 2017a; 2017b; 2017c; 2018; Ranjbaran et al., 2020a-d; Amirian and Ranjbaran, 2020; Baharvand and Ranjbaran, 2020a; 2020b). In the conventional methods of analysis, the system change information is indirectly obtained via solution of governing equations. Consequently, the conventional methods contain epistemic (lack of knowledge) uncertainty. On the other hand, in the (CSP) the system change information is directly obtained by logical reasoning, concise mathematics and reliable data. Consequently the (CSP) is free of epistemic uncertainty. Moreover the (CSP) is a free size method, i.e., it is independent of the size, material, coordinate system and etc. Consequently, it is applicable to all naturalphenomena, in different branches of human knowledge. In the presented paper the (CSP) is applied in analysis of variable data in geotechnical engineering.

\section{Basic Formulation}

The traditional formulation in the academic universe is commenced with construction of the governing differential Eq. (1), in which $(\psi)$ is the displacement function, $(n)$ is the core order of derivative and $\left(\psi^{(n)}\right)$ is the core derivative:

$$
\left(\psi^{(n)}\right)^{(n)}+\ldots=0
$$

Next step is solution of the governing equation. The procedures for solution of the governing equation are divided into the stiffness method and the flexibility method. In the stiffness method, the working parameter is selected as a decreasing system parameter called the stiffness. The governing equation for the stiffness method is in Equation (2) and shown in Fig. 1. On the other hand an increasing parameter called the flexibility, which is inverse of the stiffness, is the working parameter of the flexibility method. The governing equation for the flexibility method is in Eq. (3) and shown in Fig. 2. Equations (2) and (3) are symbolic equations in place of conventional differential and integral equations in the literature. In these equations, $\left(k_{S S}=k_{S}-k_{C}\right)$ is the survived stiffness, $\left(f_{S F}=f_{S}+f_{C}\right)$ is the survived flexibility, $\left(k_{S}\right)$ is the system-stiffness, $\left(k_{C}\right)$ is the changestiffness, $\left(f_{S}\right)$ is the system-flexibility, $\left(f_{C}\right)$ is the changeflexibility, $(F)$ is force and $(\psi)$ is displacement:

$$
\begin{gathered}
k_{S S} \psi=F \rightarrow F / \psi=k_{S S} \\
f_{S F} F=\psi \rightarrow F / \psi=1 / f_{S F}
\end{gathered}
$$

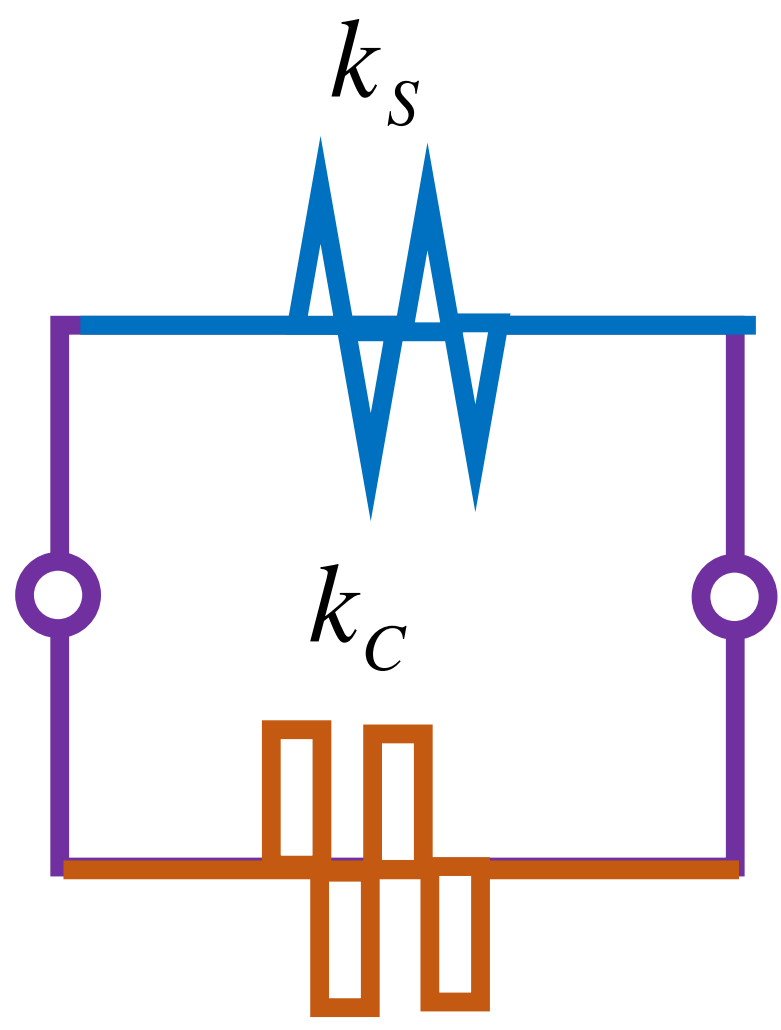

$$
k_{S S}=k_{S}-k_{C}
$$

Fig. 1: Spring-model for stiffness method

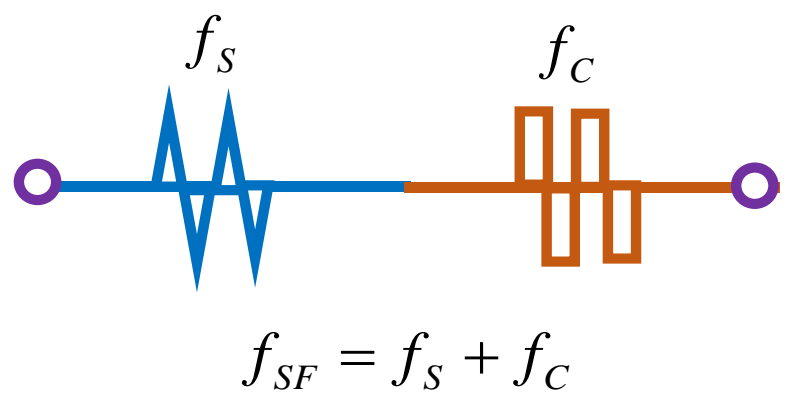

Fig. 2: Spring-model for flexibility method 
It is known that, in conventional methods, indirect computation of system parameters contains epistemic uncertainty. The main aim of the presented paper is to remove this uncertainty.

Toward the aim, the $(F)$ and $(\psi)$ are omitted from Eq. (2) and (3) as in Eq. (4), in the first step:

$$
k_{S S}=1 / f_{S F}
$$

In the next step, in view of Eq. (4) the product of equation $\left(k_{S S}=1 / f_{S F}\right)$ for the changed state and equation $\left(1 / k_{S}=f_{S}\right)$ for the intact state is expressed in Eq. (5), as shown in Fig. 3:

$$
\left(k_{S S}=\frac{1}{f_{S F}}\right) \times\left(\frac{1}{k_{S}}=f_{S}\right) \Rightarrow\left(\frac{k_{S S}}{k_{S}}=\frac{f_{S}}{f_{S F}}\right)
$$

Equation (5) is rearranged to obtain the $\left(k_{S S}\right)$ and $\left(k_{C}\right)$, in terms of the other parameters, in Eq. (6):

$$
\begin{aligned}
& k_{S S}=\frac{f_{S} \times k_{S}}{f_{S}+f_{C}}=\frac{f_{S}}{f_{S}+f_{C}} \times k_{S}=S_{R} \times k_{S} \\
& k_{C}=\frac{f_{C} \times k_{S}}{f_{S}+f_{C}}=\frac{f_{C}}{f_{S}+f_{C}} \times k_{S}=F_{R} \times k_{S}
\end{aligned}
$$

in which the phenomenon functions (collection of the failure function $\left(F_{R}\right)$ and the survive function $\left(S_{R}\right)$ are defined in Eq. (7):

$$
F_{R}=\frac{f_{C}}{f_{S}+f_{C}} \in[0,1] S_{R}=\frac{f_{S}}{f_{S}+f_{C}} \in[0,1]
$$

Definition of the dimensionless phenomenon functions in a unit interval, introduced a down to earth method for human knowledge. Therefore, the proposed method is free of the common problems in the conventional methods, such as singularity, instability and etc. Consequently the authors decided to complete the work. In order to complete the formulation, the unknown parameters in Eq. (8) should be explicitly determined:

$$
k_{C}=? f_{C}=?
$$

The investigation for explicit definition of the aforementioned functions is continued in the next paragraph via definition and construction of the so called state functions.

Development of a functional $\left(F_{R}\right.$ and $\left.S_{R}\right)$ in terms of two functions $\left(f_{S}\right.$ and $\left.f_{C}\right)$ is not possible. Therefore, the phenomenon functions are customized for $\left(k_{S}=f_{S}=1\right)$ to define the destination function $(D)$ and the origin function $(O)$, which are collectively called the state functions and the state ratio $(R)$ in Eq. (9). This is an artifice to define functions ( $D$ and $O$ ) in terms of only one variable $(R)$ :

$F_{R} \Rightarrow D \quad S_{R} \Rightarrow O \quad f_{C} \Rightarrow R$

Consequently the $(D)$ and $(O)$ are defined in terms of the $(R)$ in Eq. (10):

$D=\frac{R}{1+R} O=\frac{1}{1+R} R=\frac{D}{R}$

The state functions may be considered as solution of the boundary value problems in Eq. (11), in which $(\min )$ and $(\max )$ denote minimum and maximum respectively:

$D=\left|\begin{array}{ll}\min =0 & @ R=0 \\ \max =1 & @ R=\infty\end{array} O=\right| \begin{array}{ll}\max =1 & @ R=0 \\ \min =0 & @ R=\infty\end{array}$

The $(R)$ with one end in the infinity, as shown in Fig. 4 , is not a good working parameter. Moreover, this ratio is itself a function, so it is not wise to be used as an independent variable. Therefor, the state ratio $(\xi \in[0$, 1]) with a zero value $(\xi=0)$ at the origin and a unit value $(\xi=1)$ at the destination is defined. In terms of the state variable, the boundary value problems in Eq. (11) is rewritten in Eq. (12):

$D=\left|\begin{array}{ll}\min =0 & @ \xi=0 \\ \max =1 & @ \xi=1\end{array} O=\right| \begin{array}{ll}\max =1 & @ \xi=0 \\ \min =0 & @ \xi=1\end{array}$

Investigation for construction of solution for boundary value problems in Eq. (12), led the authors to use their experience in structural mechanics, finite element method, mathematics and extensive research (Ranjbaran et al., 2020b). The results are the state functions defined in Eq. (13) and shown in Fig. 5:

$D=0.25\left(2-1+6 \xi^{2}-4 \xi^{3}-\cos (\pi \xi)\right)$
$O=0.25\left(2+1-6 \xi^{2}+4 \xi^{3}+\cos (\pi \xi)\right)$

Equation (13) is an average of polynomial and trigonometric functions as defined in Eq. (14):

$D=0.25\left(0+6 \xi^{2}-4 \xi^{3}\right)+0.25(1-\cos \pi \xi)$
$O=0.25\left(2-6 \xi^{2}+4 \xi^{3}\right)+0.25(1+\cos \pi \xi)$

The authors invite the readers from all over the world to propose new (better in some sense) state functions in place of Eq. (13). 
Abdolrasoul Ranjbaran et al. / International Journal of Structural Glass and Advanced Materials Research 2020, Volume 4: 276.293 DOI: 10.3844/sgamrsp.2020.276.293

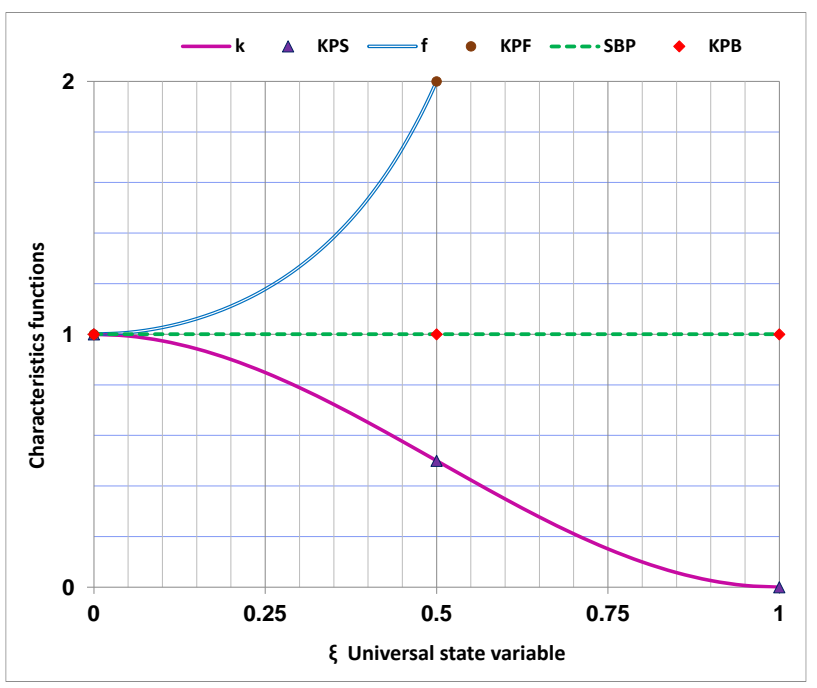

Fig. 3: Change of state philosophy basic equation

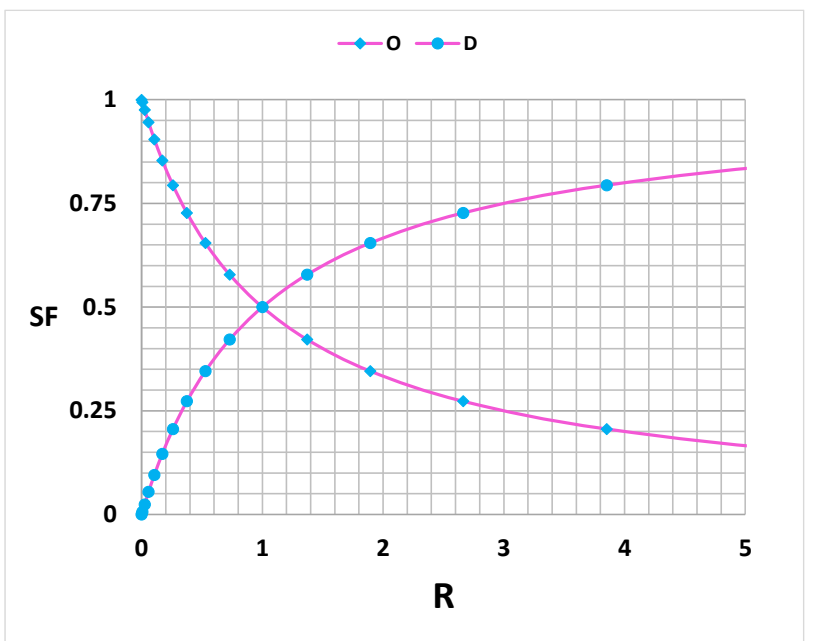

Fig. 4: State Functions versus the state ratio

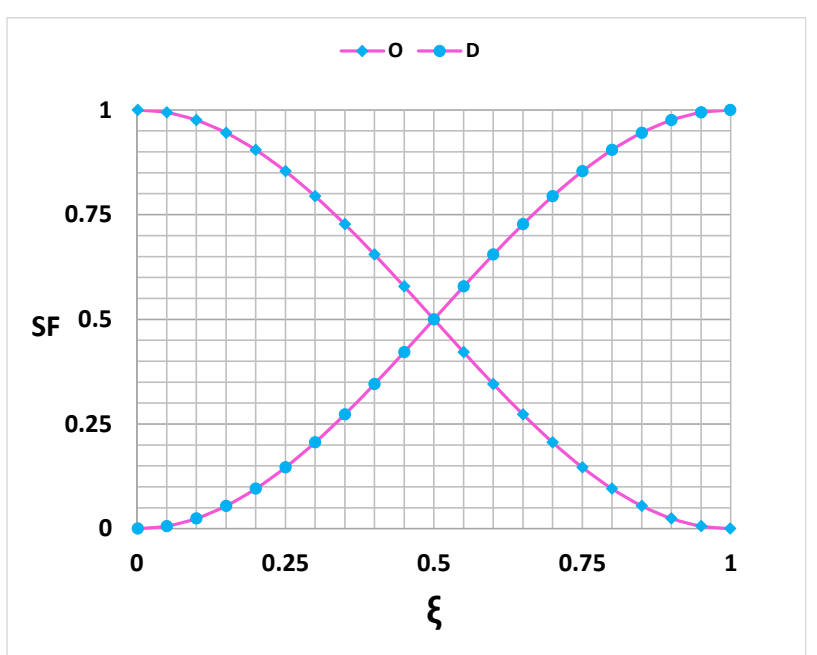

Fig. 5: State functions versus the state variable 
Now attention is paid to construction of the phenomenon functions. Via the definition of the $\left(k_{S S}\right)$ and the $\left(f_{S F}\right)$ and the crack compliance $\left(f_{C}\right)$ in fracture mechanics (Anderson, 2005), the authors detected a fact that, the $\left(f_{C}\right)$ is directly proportional to the $\left(k_{S}\right)$ ! This detection is called "the Persian Principle of Change (PPC)". In view of this principle the $\left(f_{C}\right)$ is defined in Eq. (15):

$$
f_{C} / R=k_{S} / 1 f_{C}=k_{S} R f_{C}=k_{S} D / O
$$

Note that Eq. (15) is an alternative for the whole fracture mechanics (Anderson, 2005)! Insertion of Eq. (15) into Eq. (7) concluded in the general definition for the phenomenon functions in Eq. (16):

$$
F_{R}=\frac{k_{S}^{2} D}{O+k_{S}^{2} D} S_{R}=\frac{O}{O+k_{S}^{2} D}
$$

The $\left(k_{S}\right)$ is not explicitly known so it is not a feasible working parameter. Toward better definition, Eq. (16) is rewritten in Eq. (17) in terms of the positive control parameters $\left(a_{M}\right)$ and (b) (Ranjbaran et al., 2020b). The flexibility for translation and rotation of phenomenon functions in the $(1 \times 1)$ working box, which let the experts to enforce their will, is provided by selection of two control parameters from calibration of reliable data:

$$
F_{R}=\frac{a_{M} D^{b}}{O^{b}+a_{M} D^{b}} S_{R}=\frac{O^{b}}{O^{b}+a_{M} D^{b}}
$$

To this end the proposed formulation is mathematically in abstract form. Consequently, it is a universal formulation, in a sense that it is independent of geometry, coordinates, material properties, size and changing agent. Therefore it is equally applies to all natural phenomena.

\section{Persian Curve}

As observed, the proposed formulation is derived based on logical reasoning and concise mathematics. Moreover, there was no need for construction of differential and integral equations, which is the paramount basis of the conventional methods of analysis in human knowledge. Consequently, the proposed formulation is reliable and free of epistemic uncertainty, because it is based on obvious and certain basis, for example the definition of flexibility as inverse of stiffness in Eq. (4).

For a given phenomenon, the lifetime is truncated at a workable interval $\left(\lambda \in\left[\lambda_{O}, \lambda_{T}\right]\right)$ and is mapped onto the state variable as in Eq. (18), where $\left(\lambda_{O}\right)$ is the origin point $(O)$ and $\left(\lambda_{T}\right)$ is the end point of lifetime respectively:

$$
\lambda=(1-\xi) \lambda_{o}+(\xi) \lambda_{T} \xi=\left(\lambda-\lambda_{o}\right) /\left(\lambda_{T}-\lambda_{T}\right)
$$

In terms of the lifetime, the $\left(F_{R}\right)$ is renamed as Persian-Fasa-curve $\left(P_{F}\right)$, the $\left(S_{R}\right)$ is renamed as Persian-Shiraz-curve $\left(P_{S}\right)$ and the two collectively called the Persian curve $\left(P_{C}\right)$, defined in Eq. (19), in which $\left(P_{O}\right)$ is the ordinate of the origin point $(O)$ and $\left(P_{T}\right)$ is the ordinate of the truncated (end) point $(T)$. Note that insertion of $\left(P_{O}=1\right.$ and $\left.P_{T}=0\right)$ and $\left(P_{O}=0\right.$ and $\left.P_{T}=1\right)$ into Eq. (19) conclude into $\left(F_{R}\right)$ and $\left(S_{R}\right)$ respectively as in Eq. (17):

$$
P_{C}=\left(P_{O} O^{b}+P_{T} a_{M} D^{b}\right) /\left(O^{b}+a_{M} D^{b}\right)
$$

In comply with the vocabulary of human knowledge, the $\left(P_{S}\right)$ is the unified equation for capacity and reliability representing a decreasing data and the $\left(P_{F}\right)$ is the unified equation for the probability and fragility representing an increasing data. Moreover, in comply with the common practice in stochastic analysis the (probability) density distribution, here called the PersianZahedan-curve $\left(P_{Z}\right)$, is defined as the derivative of phenomenon functions with respect to the $(\xi)$, in Eq. (20), in which $\left(F_{R}^{(1)}, S_{R}^{(1)}\right.$ and $\left.D^{(1)}\right)$ are derivatives of $\left(F_{R}, S_{R}\right.$ and $D$ ) with respect to $(\xi)$ respectively. In spite of the paramount role of the density distribution in stochastic theory, it has no role in the (CSP) and it is used only for comparison with the conventional one:

$$
F_{R}^{(1)}=+P_{Z} S_{R}^{(1)}=-P_{Z} P_{Z}=\frac{b a_{M} D^{b-1} O^{b-1} D^{(1)}}{\left(O^{b}+a_{M} D^{b}\right)^{2}}
$$

Toward determination of control parameters, Eq. (19) is rearranged as in Eq. (21):

$$
(D / O)^{b} a_{M}=\left(P_{C}-P_{O}\right) /\left(P_{T}-P_{C}\right)
$$

In view of Eq. (21) and noting that at $(M)\left(D_{M} / O_{M}=1\right)$ then $\left(a_{M}\right),\left(a_{N}\right)$ and $(b)$, for a reliable decreasing data as shown in Fig. 6 or for a reliable increasing data as shown in Fig. 7 are obtained in terms of the Key Points coordinates (KPS), in Eq. (22), see Appendix:

$a_{N}=\frac{P_{N}-P_{O}}{P_{T}-P_{N}} a_{M}=\frac{P_{M}-P_{O}}{P_{T}-P_{M}} b=\frac{\log \left(a_{N} / a_{M}\right)}{\log \left(D_{N} / O_{N}\right)}$

The Key Points (KPS) are defined as the Origin point $(O)$, the Middle point $(M)$, the end point $(T)$ and the Next point $(N)$ (a point between the other three), in Eq. (23) and shown in Figs. 6 and 7 for decreasing and increasing data respectively:

$O\left(0.0, P_{O}\right) N\left(\xi_{N}, P_{N}\right) M\left(0.5, P_{M}\right) T\left(1.0, P_{T}\right)$ 


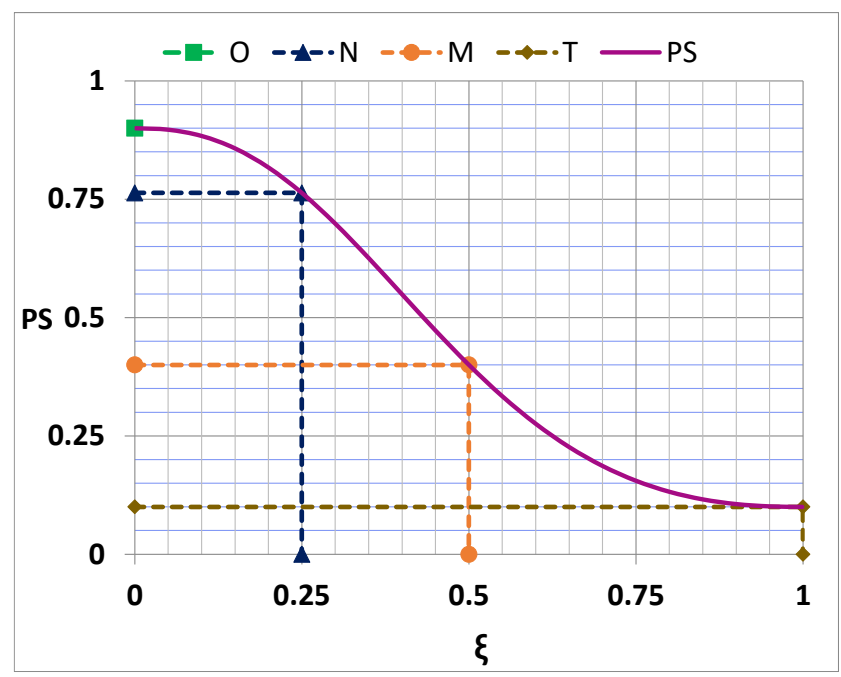

Fig. 6: Key points on Persian-Shiraz-curve

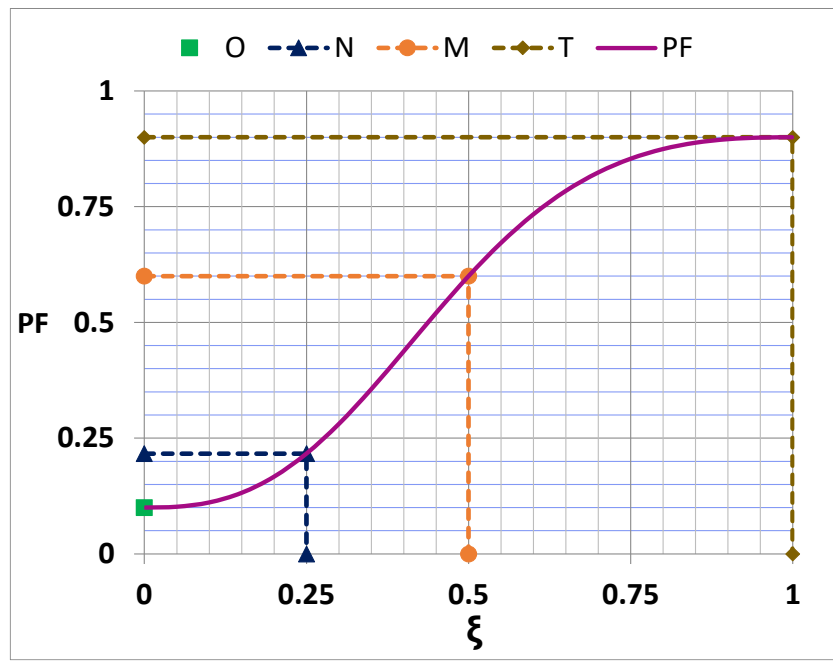

Fig. 7: Key points on Persian-Fasa-curve

The $(O)$ and $(T)$ points are used for mapping in Eq. (18) and $(N)$ and $(M)$ are used for $\left(a_{M}\right)$ and $(b)$ computation in Eq. (22). The (PC) solves quite nonlinear problems without any iteration but with simple and accurate artifice. Note that the (PC), similar to a natural phenomenon, is independent of, any coordinate system and any man made principle.

\section{Persian Curve Interpretation}

For the case of lifetime as value of real world data (as geotechnical data in this study), the Persian Curves are interpreted as follows. The value of $\left(P_{S}\right)$ for a data point $\left(\lambda_{A}\right)$ denotes the ratio of number of data $\left(n_{S}\right)$ greater than $\left(\lambda_{A}\right)$ over the total number of data $\left(n_{t}\right)$. It is a weight for data in the upper region. Similarly, the value of $\left(P_{F}\right)$ for a data point $\left(\lambda_{A}\right)$ denotes the ratio of number of data $\left(n_{F}\right)$ less than $\left(\lambda_{A}\right)$ over the total number of data $\left(n_{t}\right)$. It is a weight for data in the lower region.

For the case of lifetime as a parameter of the system (such as relative slenderness ratio of structures), the Persian Curves are interpreted as follows. The value of $\left(P_{S}\right)$ for a data point $\left(\lambda_{A}\right)$ denotes efficiency of the system, while the system-deficiency is denoted by the value of $\left(P_{F}\right)$.

\section{Analysis of Reliable Data}

The (CSP) has great similarity with the probability theory. This is taken for granted to increase the reliability of analysis. The $\left(P_{F}\right)$ is equivalent to the Cumulative Distribution Function $(\mathrm{CDF})$ and the $\left(P_{Z}\right)$ is equivalent to the Probability Density Function (PDF). In probability theory the (PDF) plays the paramount role. 
Different probability distributions are classified according to their $(P D F$ 's). Determination of the $(C D F)$ from the $(P D F)$ is a difficult process. Moreover limited number of $(P D F s)$ adds to the uncertainty of the results and necessitates the development of new $(P D F)$ for new problems in all branches of human knowledge. That is not the case for the $(C S P)$, where the $\left(P_{F}\right)$ as a pseudo $(C D F)$ is directly determined from the reliable data. So it is simple, cheap and accurate. There is no need for the $(P D F)$ at all. It is added for completeness and comparison with the results of the others in the literature.

Within the field of geotechnical engineering, real world problems are treated and this is inevitably associated with uncertainties arising from various sources. The sources of uncertainty may be related to uncertainties of nature and uncertainties of mind, often referred to aleatory and epistemic uncertainties respectively. In view of the logical reasoning leading to the Persian curve, the uncertainty of mind is omitted. There remained the uncertainty of nature which is gradually reduced by providing more reliable data. Therefore in this study the data is treated as varying instead of uncertain. Analysis of data is conducted in the following steps. Step I: Divide the data between its minimum and maximum, into several intervals (preferably more than 10). Step II: Determine the frequencies (histogram) for the selected intervals (use the frequency function in Excel software). Step III: Cumulate the frequencies in Step II to obtain the cumulative data. Scale the data and cumulative data into unit intervals. Step IV: Select the key points as in Eq. (23) and compute the control parameters as in Eq. (22). Step V: Compute the Persian curves from Eq. (19) and the density curve from Eq. (20).

In the following examples varying reliable data are managed in a form to prepare for reduction of uncertainties in the art of decision making in practical geotechnical engineering.

\section{Example 1}

Analyze the warehouse live load data $(\lambda)$ by (Baker, 1990; Kanwar, 2018).

\section{Solution}

The measured values of live load on the warehouse floor is shown in Table 1a. The corresponding density and the cumulative distribution (cum) are computed and shown in Table $1 \mathrm{~b}$ and is denoted by (WLL). The Key Points $(K P F)$ is shown in Eq. (24). The control parameters are shown in Eq. (25). The Persian-Fasacurve $(P F R)$, the Persian-Shiraz-curve $(P S R)$ and the Persian-Zahedan-curve $(P Z R)$ are shown in Fig. 8:

$$
\begin{aligned}
& O(0.0,0.0) N(0.25,0.33) M(0.5,0.77) T(1.0,1.0) \\
& \lambda=238 \xi \text { cum }=220 P_{C} a_{M}=3.347 b=1.138
\end{aligned}
$$

The same data is analyzed by (Kanwar, 2018). The proposed formulation is exact and is more than hundred times simpler than that of the (Kanwar, 2018).

\section{Example 2}

The data of basalt rock uniaxial compressive strength parameter $(S)$ are taken from (Cui et al., 2017) and shown in Table 2a. Analyze the data by the Persian curve method.

\section{Solution}

For the given data, the frequencies and cumulative data (cum) (BASALT) computed, as in Table $2 \mathrm{~b}$ and shown in Fig. 9. Then the key points are selected as in Eq. (26). The selected key points are used to calculate the control parameters in Eq. (27). Finally, the Persian-Fasacurve $(P F R)$, the Persian-Shiraz-curve (PSR) and the Persian-Zahedan-curve $(P Z R)$ are shown in Fig. 9:

$$
\begin{aligned}
& O(0.0,0.0) N(0.25,0.15) M(0.50,0.58) T(1.0,1.0) \\
& S=150 \xi+50 \text { cum }=220 P_{C} a_{M}=1.38 b=1.19
\end{aligned}
$$

\section{Example 3}

The Nipigon River landslide occurred on the morning of April 23rd 1990, at the north area of the town of Nipigon, Ontario, Canada. The results of 121 corrected un-drained shear strength $(V)$ at the Nipigon river slope is shown in Table 3a (Kanwar, 2018). Analyze the data by the Persian curve method.

\section{Solution}

For the given data, the frequencies and the cumulative data (cum) (NIPIG) are computed, as in Table $3 \mathrm{~b}$ and shown in Fig. 10. Then the key points are selected as in Eq. (28). The selected key points are used for determination of the control parameters as expressed in Eq. (29). Finally the Persian-Fasa-curve (PFR), the Persian-Shiraz-curve (PSR) and the Persian-Zahedancurve (PZR) are shown in Fig. 10. Simplicity and accuracy of the presented formulation for the case of the Nipigon river slope is a good index for verification of the proposed work:

$$
\begin{aligned}
& O(0.0,0.0) N(0.25,0.38) M(0.5,0.83) T(1.0,1.0) \\
& V=140 \xi \text { cum }=122 P_{C} a_{M}=4.88 b=1.20
\end{aligned}
$$

\section{Example 4}

The uniaxial compressive strength $(S)$ of rock from an open-pit slope of China (Deng et al., 2004), is shown in Table 4a. Analyze the data by the Persian curve method. 
Abdolrasoul Ranjbaran et al. / International Journal of Structural Glass and Advanced Materials Research 2020, Volume 4: 276.293 DOI: 10.3844/sgamrsp.2020.276.293

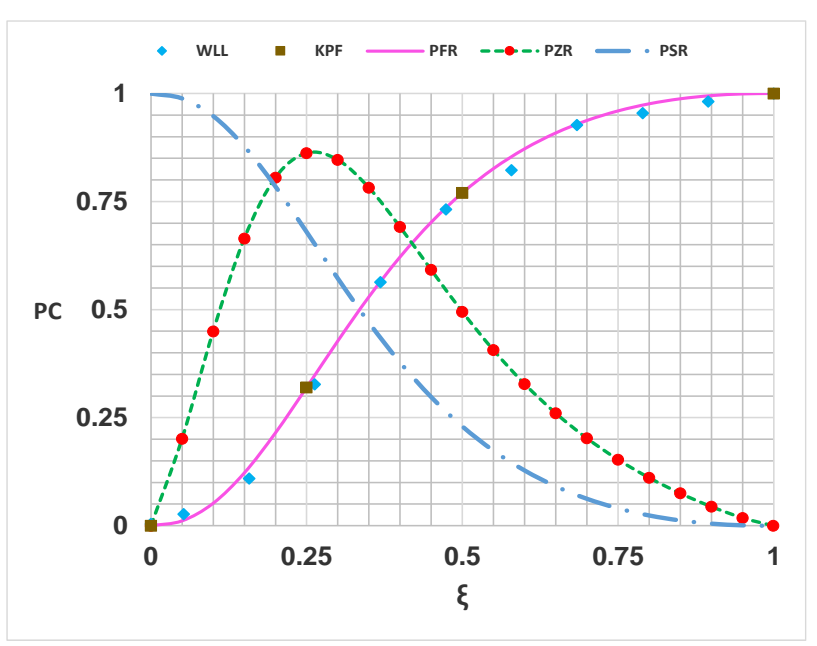

Fig. 8: Analysis of warehouse live loads

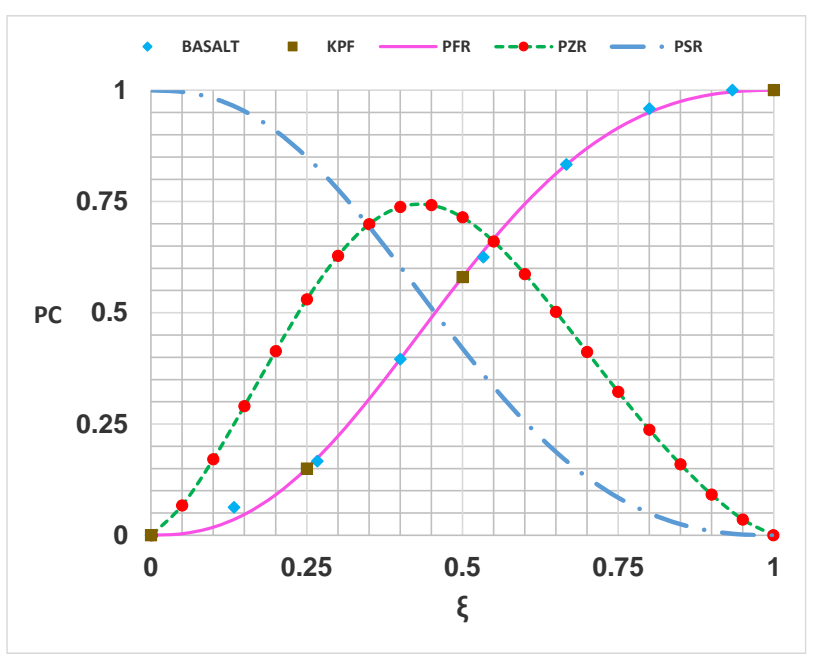

Fig. 9: Persian analysis of Basalt rock uniaxial strength data.

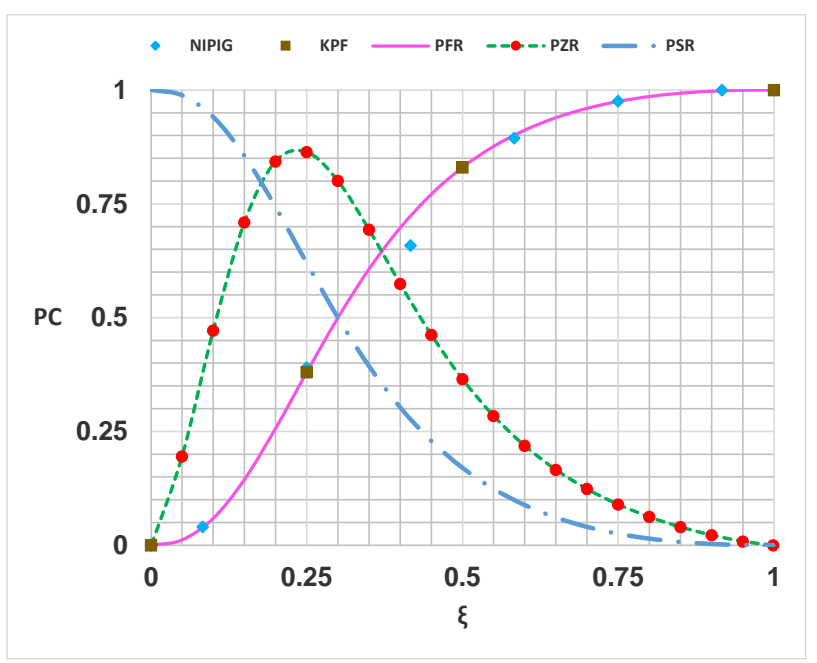

Fig. 10: Persian analysis of shear strength on Nipigon river slope 
Abdolrasoul Ranjbaran et al. / International Journal of Structural Glass and Advanced Materials Research 2020, Volume 4: 276.293 DOI: 10.3844/sgamrsp.2020.276.293

Table 1a: Data of 220 sample values of warehouse live load (Psf)

Data 220 sample warehouse live load

\begin{tabular}{|c|c|c|c|c|c|c|c|c|c|}
\hline 0 & 7.8 & 36.2 & 60.6 & 64.0 & 64.2 & 79.2 & 88.4 & 38.0 & 72.7 \\
\hline 72.2 & 72.6 & 74.4 & 21.8 & 17.1 & 48.5 & 16.8 & 105.9 & 57.2 & 75.7 \\
\hline 225.7 & 42.5 & 59.8 & 41.7 & 39.9 & 55.5 & 67.2 & 122.8 & 45.2 & 62.9 \\
\hline 55.1 & 55.9 & 87.7 & 59.2 & 63.1 & 58.8 & 67.7 & 90.4 & 43.3 & 55.2 \\
\hline 36.6 & 26.0 & 90.5 & 23.0 & 43.5 & 52.1 & 102.1 & 71.7 & 4.1 & 37.3 \\
\hline 129.4 & 66.4 & 138.7 & 127.9 & 90.9 & 46.9 & 197.5 & 151.1 & 157.3 & 197.0 \\
\hline 134.6 & 73.4 & 80.9 & 53.3 & 80.1 & 62.9 & 150.8 & 102.2 & 6.4 & 45.4 \\
\hline 121.0 & 106.2 & 94.4 & 139.6 & 152.5 & 70.2 & 111.8 & 174.1 & 85.4 & 83.0 \\
\hline 178.8 & 30.2 & 44.1 & 157.0 & 105.3 & 87.0 & 50.1 & 198.0 & 86.7 & 64.6 \\
\hline 78.6 & 37.0 & 70.7 & 83.0 & 179.7 & 180.2 & 60.6 & 212.4 & 72.2 & 86.0 \\
\hline 95.4 & 24.1 & 87.3 & 80.6 & 74.8 & 72.4 & 131.1 & 116.1 & 53.6 & 99.1 \\
\hline 40.2 & 23.4 & 8.4 & 42.6 & 43.4 & 27.4 & 63.8 & 18.4 & 16.2 & 58.7 \\
\hline 92.2 & 49.8 & 50.9 & 116.4 & 122.9 & 132.3 & 105.2 & 160.3 & 28.7 & 46.8 \\
\hline 99.5 & 106.9 & 55.9 & 136.8 & 110.4 & 123.5 & 92.4 & 160.9 & 45.4 & 96.3 \\
\hline 88.5 & 48.4 & 62.3 & 71.3 & 133.2 & 92.1 & 111.7 & 67.9 & 53.1 & 39.7 \\
\hline 93.2 & 55.0 & 80.8 & 143.5 & 122.3 & 184.2 & 150.0 & 57.6 & 6.8 & 53.3 \\
\hline 96.1 & 54.8 & 63.0 & 228.3 & 139.3 & 59.1 & 112.1 & 50.9 & 158.6 & 139.1 \\
\hline 213.7 & 65.7 & 90.3 & 198.4 & 97.5 & 155.1 & 163.4 & 155.3 & 229.5 & 75.0 \\
\hline 137.6 & 62.5 & 156.5 & 154.1 & 134.3 & 81.6 & 194.4 & 155.1 & 89.3 & 73.4 \\
\hline 79.8 & 68.7 & 85.6 & 141.6 & 100.7 & 106.0 & 131.1 & 157.4 & 80.2 & 65.0 \\
\hline 78.5 & 118.2 & 126.4 & 33.8 & 124.6 & 78.9 & 146.0 & 100.3 & 97.8 & 75.3 \\
\hline 24.8 & 55.6 & 135.6 & 56.3 & 66.9 & 72.2 & 105.4 & 98.9 & 101.7 & 58.2 \\
\hline
\end{tabular}

Table 1b: Frequencies and cumulative data for warehouse live load

Frequencies and cumulative data for 220 sample warehouse live load $\xi=W L / 237.5 W L L=C U M / 220$

\begin{tabular}{llllll} 
C01 & C02 & C03 & C04 & C05 & C06 \\
No. & WL & $\xi$ & $n$ & CUM & WLL \\
\hline 1 & 0.0 & 0.0000 & 1 & 6 & 0.0045 \\
2 & 12.5 & 0.0526 & 5 & 24 & 0.0273 \\
3 & 37.5 & 0.1579 & 18 & 72 & 0.1091 \\
4 & 62.5 & 0.2631 & 48 & 124 & 0.3272 \\
5 & 87.5 & 0.3684 & 52 & 161 & 0.5636 \\
6 & 112.5 & 0.4737 & 20 & 181 & 0.7318 \\
7 & 137.5 & 0.5789 & 23 & 204 & 0.9272 \\
8 & 162.5 & 0.6842 & 6 & 210 & 0.9545 \\
9 & 187.5 & 0.7895 & 6 & 216 & 0.9818 \\
10 & 212.5 & 0.8947 & 4 & 220 & 1.0000 \\
11 & 237.5 & 1.0000 & & & \\
\hline
\end{tabular}

Table 2a: Data of 48-basalt rock uniaxial compressive strength (MPa)

\begin{tabular}{|c|c|c|c|c|c|c|c|c|c|}
\hline No. & $S_{U}$ & No. & $S_{U}$ & No. & $S_{U}$ & No. & $S_{U}$ & No. & $S_{U}$ \\
\hline 1 & 61.2 & 11 & 106.4 & 21 & 125.8 & 31 & 140.7 & 41 & 162.6 \\
\hline 2 & 63.2 & 12 & 109.7 & 22 & 128.9 & 32 & 142.2 & 42 & 165.3 \\
\hline 3 & 66.6 & 13 & 112.0 & 23 & 129.2 & 33 & 142.6 & 43 & 165.5 \\
\hline 4 & 86.5 & 14 & 112.0 & 24 & 129.6 & 34 & 144.4 & 44 & 167.9 \\
\hline 5 & 90.8 & 15 & 114.6 & 25 & 129.6 & 35 & 147.5 & 45 & 174.7 \\
\hline 6 & 97.7 & 16 & 114.9 & 26 & 131.8 & 36 & 148.9 & 46 & 177.2 \\
\hline 7 & 98.0 & 17 & 115.0 & 27 & 136.4 & 37 & 150.9 & 47 & 191.7 \\
\hline 8 & 99.7 & 18 & 118.7 & 28 & 137.4 & 38 & 152.5 & 48 & 191.9 \\
\hline 9 & 102.4 & 19 & 119.7 & 29 & 139.0 & 39 & 152.9 & 49 & \\
\hline 10 & 104.3 & 20 & 123.2 & 30 & 140.0 & 40 & 159.1 & 50 & \\
\hline
\end{tabular}


Table 2b: Frequencies and cumulative data for 48-basalt strength (MPa)

Frequencies and cumulative data for 48 -basalt strength

$\xi=\left(S_{U}-50\right) / P B A S=C U M / 48$

\begin{tabular}{llllll} 
C01 & C02 & C03 & C04 & C05 & CUM \\
No. & $S_{U}$ & $\xi$ & $n$ & 0 & PBAS \\
\hline 1 & 50 & 0.0000 & 0 & 3 & 0.0 .00 \\
2 & 70 & 0.1333 & 3 & 8 & 0.0625 \\
3 & 90 & 0.2667 & 5 & 19 & 0.1667 \\
4 & 110 & 0.4000 & 11 & 30 & 0.3958 \\
5 & 130 & 0.5333 & 10 & 40 & 0.6250 \\
6 & 150 & 0.6667 & 6 & 46 & 0.9333 \\
7 & 170 & 0.8000 & 2 & 48 & 1.0000 \\
8 & 190 & 0.9333 & 0 & 48 & 1.0000 \\
9 & 200 & 1.0000 & & & \\
10 & & & & & \\
\hline
\end{tabular}

Table 3a: Corrected undrained shear strength values at the Nipigon river slope (121)

\begin{tabular}{|c|c|c|c|c|c|c|c|}
\hline \multicolumn{8}{|c|}{ Undrained shear strength $(\mathrm{kPa})$ at the Nipigon river slope } \\
\hline 60.8 & 56.05 & 52.25 & 41.80 & 80.75 & 18.05 & 23.75 & 32.30 \\
\hline 61.75 & 56.05 & 52.25 & 41.75 & 38.95 & 18.05 & 25.65 & 33.25 \\
\hline 61.75 & 57.00 & 52.25 & 44.65 & 39.90 & 19.00 & 26.60 & 33.25 \\
\hline 62.7 & 57.00 & 52.20 & 44.65 & 39.90 & 19.00 & 26.60 & 33.25 \\
\hline 63.65 & 57.00 & 53.20 & 81.70 & 39.90 & 19.00 & 27.55 & 35.15 \\
\hline 64.6 & 57.00 & 53.20 & 84.55 & 39.90 & 20.90 & 28.50 & 36.10 \\
\hline 64.6 & 57.95 & 54.15 & 85.50 & 39.90 & 20.90 & 29.45 & 37.05 \\
\hline 64.6 & 57.95 & 45.60 & 87.40 & 39.90 & 22.80 & 33.25 & 37.05 \\
\hline 64.6 & 57.95 & 46.55 & 95.00 & 40.85 & 22.80 & 33.25 & 114.00 \\
\hline 65.55 & 58.90 & 47.50 & 95.00 & 40.85 & 23.75 & 38.00 & \\
\hline 68.4 & 54.15 & 49.40 & 95.00 & 41.80 & 33.25 & 38.00 & \\
\hline 65.55 & 55.10 & 49.40 & 96.90 & 29.45 & 33.25 & 38.00 & \\
\hline 68.4 & 55.10 & 51.30 & 74.10 & 30.40 & 34.20 & 38.00 & \\
\hline 68.4 & 68.40 & 104.50 & 67.45 & 32.30 & 35.15 & 38.00 & \\
\hline 66.5 & 71.25 & 71.25 & 77.90 & 77.90 & 80.75 & 38.00 & \\
\hline 66.5 & 66.50 & 66.50 & 67.45 & 68.40 & 68.40 & 104.50 & \\
\hline
\end{tabular}

Table 3b: Frequencies and cumulative data for shear strength at the Nipigon river slope $(k P a)$

Frequencies and cumulative data for shear strength $(\mathrm{kPa})$

$\xi=S_{C} / 140 N I P I=C U M / 122$

\begin{tabular}{|c|c|c|c|c|c|}
\hline C01 & $\mathrm{C} 02$ & $\mathrm{C} 03$ & $\mathrm{C} 04$ & $\mathrm{C} 05$ & $\mathrm{C} 06$ \\
\hline No. & $S_{U}$ & $\xi$ & $n$ & $C U M$ & NIPI \\
\hline 1 & 0 & 0.0000 & 0 & 0 & 0.0000 \\
\hline 2 & 10 & 0.0714 & 1 & 1 & 0.0082 \\
\hline 3 & 30 & 0.2143 & 18 & 19 & 0.1557 \\
\hline 4 & 50 & 0.3571 & 41 & 60 & 0.4918 \\
\hline 5 & 70 & 0.5000 & 44 & 104 & 0.8525 \\
\hline 6 & 90 & 0.6428 & 11 & 115 & 0.9426 \\
\hline 7 & 110 & 0.7857 & 6 & 121 & 0.9918 \\
\hline 8 & 130 & 0.9286 & 1 & 122 & 1.0000 \\
\hline 9 & 140 & 1.0000 & 0 & 122 & 1.0000 \\
\hline \multicolumn{6}{|l|}{10} \\
\hline 11 & & & & & \\
\hline
\end{tabular}

\section{Solution}

For the given data, the frequencies and the cumulative data (cum) (CST) are computed as in Table $4 \mathrm{~b}$ and shown in Fig. 11. The key points are selected as in Eq. (30). The selected key points are used for determination of the control parameters in Eq. (31). Then the Persian-Fasacurve (PFR), the Persian-Shiraz-curve (PSR) and the Persian-Zahedan-curve (PZR) are shown in Fig. 11. In order to see the excellence of the proposed work, the interested reader may refer to Example 1 in chapter 3 of (Singh, 2018) master thesis: 


$$
\begin{aligned}
& O(0.0,0.0) N(0.25,0.15) M(0.5,0.63) T(1.0,1.00) \\
& S=9 \xi+25 \mathrm{cum}=50 P_{C} a_{M}=1.70 b=1.32
\end{aligned}
$$

\section{Example 5}

The measurement from the field Vane tests (V) (Singh, 2018), is casted in Table 5a. Analyze the data by the Persian curve method.

\section{Solution}

The frequencies and the cumulative data (cum) (VST) for the vane shear data are computed as in Table 5b and shown in Fig. 12. Then the key points are selected as in Eq. (32). The selected key points are used for determination of the control parameters in Eq. (33). Finally the Persian-Fasa-curve (PFR), the Persian-Shirazcurve (PSR) and the Persian-Zahedan-curve (PZR) are shown in Fig. 12. In order to see the beauty and excellence of the proposed work, the interested reader may refer to section 3.3.2 of (Singh, 2018) master thesis:

$$
\begin{aligned}
& O(0.0,0.0) N(0.25,0.40) M(0.5,0.80) T(1.0,1.0) \\
& V=80 \xi+30 \mathrm{cum}=41 P_{C} a_{M}=4.0 b=1.04
\end{aligned}
$$

\section{Example 6}

The cohesion data of fine grained alluvial soils at the Paglia River alluvial plain in Central Italy (Di Matteo et al., 2013) is casted in Table 6a. Analyze the data by the Persian curve method.

\section{Solution}

The frequencies and the cumulative data (cum) (CPT) for cohesion (C) are computed as in Table $6 \mathrm{~b}$ and shown in Fig. 13. Then the key points are selected as in Equation (34). The selected key points are used for determination of the control parameters in Equation (35). At this stage the Persian-Fasa-curve (PFR), the PersianShiraz-curve (PSR) and the Persian-Zahedan-curve (PZR) are shown in Fig. 13. In order to see the excellence of the proposed work, the interested reader may refer to Example 2 in chapter 3 of (Singh, 2018) master thesis:

$O(0.0,0.0) N(0.25,0.13) M(0.5,0.43) T(1.0,1.0)$

$C=18 \xi+10 \mathrm{cum}=50 P_{C} a_{M}=0.75 b=0.94$

\section{Example 7}

The shear angle data of fine grained alluvial soils at the Paglia River alluvial plain in Central Italy, (Di Matteo et al., 2013), is casted in Table 7a. Analyze the data by the Persian curve method.

\section{Solution}

The frequencies and the cumulative data (cum) (PHIT) for shear angle $(\phi)$ are computed as in Table $7 \mathrm{~b}$ and shown in Fig. 14. Then the key points are selected as in Equation (36). The selected key points are used for determination of the control parameters in Eq. (37). Then the Persian-Fasa-curve (PFR), the Persian-Shiraz-curve (PSR) and the Persian-Zahedan-curve (PZR) are shown in Fig. 14. In order to see the excellence of the proposed work, the interested reader may refer to Example 2 in chapter 3 of (Singh, 2018), master thesis:

$$
\begin{aligned}
& O(0.0,0.0) N(0.25,0.30) M(0.5,0.70) T(1.0,1.0) \\
& \varphi=4.5 \xi+25 \mathrm{cum}=57 P_{C} a_{M}=2.33 b=0.98
\end{aligned}
$$

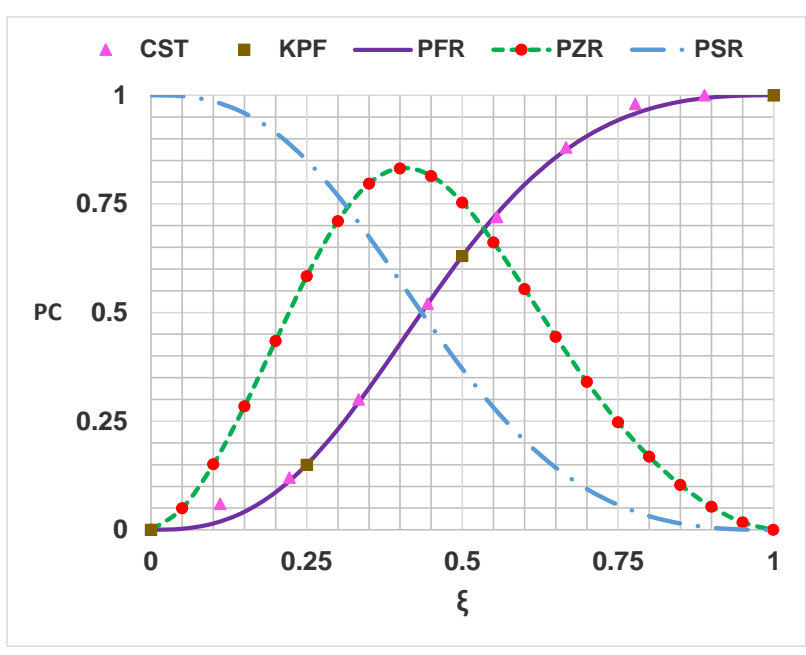

Fig. 11: Analysis of data for an open pit slope of China 
Abdolrasoul Ranjbaran et al. / International Journal of Structural Glass and Advanced Materials Research 2020, Volume 4: 276.293 DOI: $10.3844 /$ sgamrsp.2020.276.293

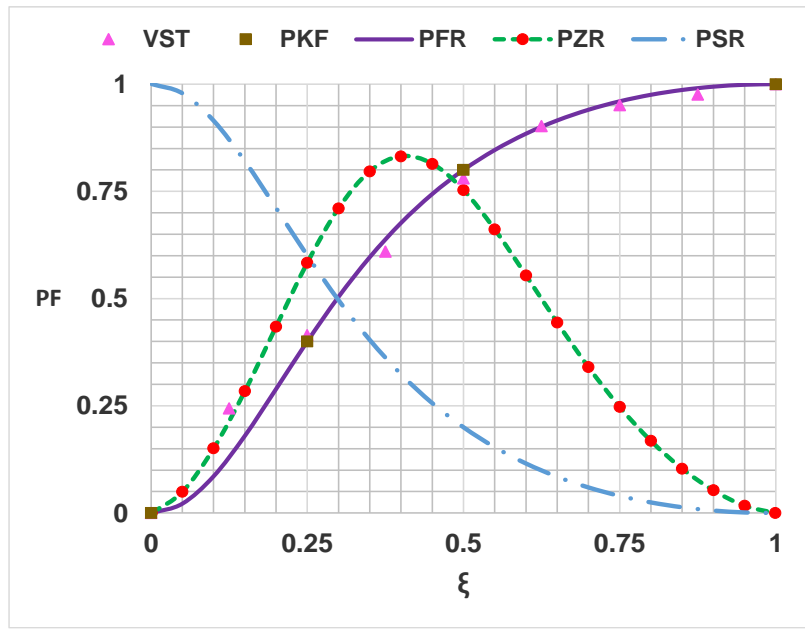

Fig. 12: Persian analysis for vane shear strength data

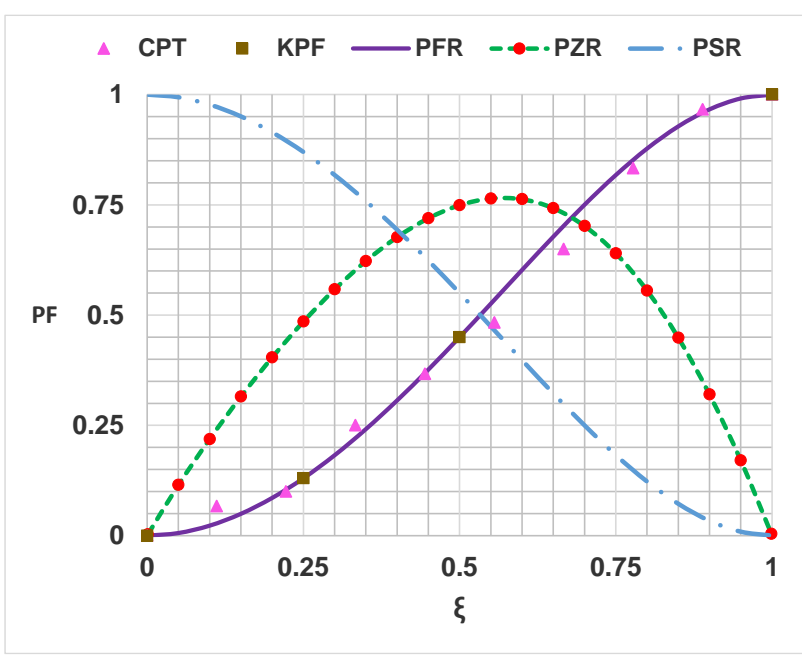

Fig. 13: Persian analysis for cohesion data

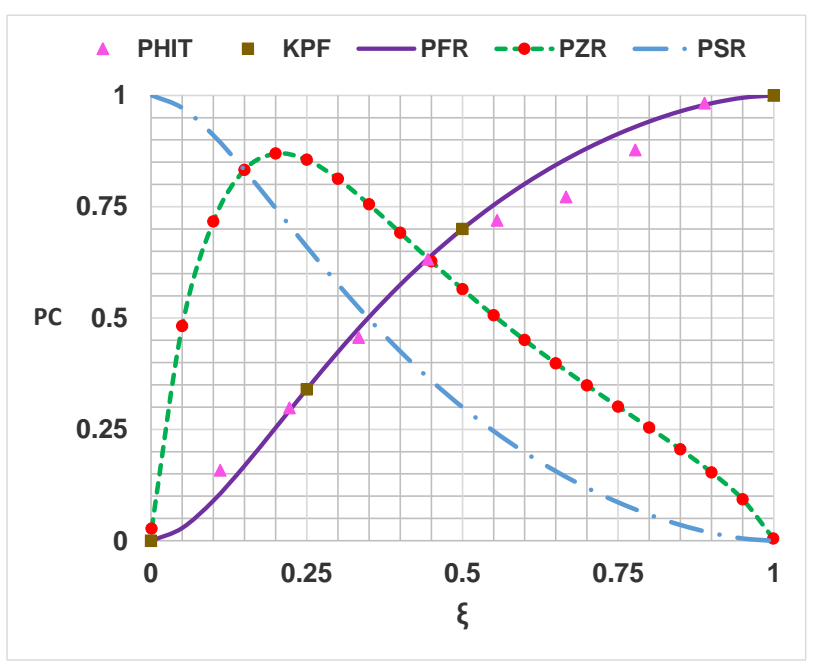

Fig. 14: Persian analysis of shear angle data 
Abdolrasoul Ranjbaran et al. / International Journal of Structural Glass and Advanced Materials Research 2020, Volume 4: 276.293 DOI: 10.3844/sgamrsp.2020.276.293

Table 4a: Data of uniaxial compressive strength (MPa), (Deng et al., 2004; Singh, 2018)

Uniaxial compressive strength (MPa)

\begin{tabular}{llllllll}
\hline 29 & 27.4 & 26.8 & 27.1 & 30.7 & 27.3 & 26.6 & 28.9 \\
30.4 & 29.9 & 29.3 & 28.3 & 28.3 & 28.2 & 28.2 & \\
31.7 & 28.8 & 27.3 & 32.4 & 31.5 & 29.5 & 25.7 & \\
26 & 29.1 & 28.0 & 29.6 & 26.4 & 31.3 & 28.5 \\
28.2 & 30.2 & 29.8 & 30.9 & 31.1 & 30.6 & 28.7 \\
27.9 & 25.2 & 28.0 & 30.6 & 27.8 & 29.4 & 31.3 & \\
26.5 & 28.4 & 30.1 & 29.2 & 29.6 & 31.0 & 29.4 \\
\hline
\end{tabular}

Table 4b: Frequencies and cumulative data for uniaxial compressive strength (MPa)

Frequencies and cumulative data for uniaxial compressive strength (MPa)

$\xi=\left(S_{C}=25\right) / 9 C S T=C U M / 50$

\begin{tabular}{llllll} 
C01 & C02 & C03 & C04 & C05 & CUM \\
No. & $S_{C}$ & $\xi$ & $n$ & 0 & CST \\
\hline 1 & 25 & 0.0000 & 0 & 3 & 0.00 \\
2 & 26 & 0.1111 & 3 & 6 & 0.06 \\
3 & 27 & 0.2222 & 3 & 15 & 0.12 \\
4 & 28 & 0.3333 & 11 & 26 & 0.30 \\
5 & 29 & 0.4444 & 10 & 36 & 0.52 \\
6 & 30 & 0.5555 & 8 & 44 & 0.72 \\
7 & 31 & 0.6666 & 5 & 49 & 0.88 \\
8 & 32 & 0.7777 & 1 & 50 & 0.98 \\
9 & 33 & 0.8888 & 0 & 50 & 1.00 \\
10 & 34 & 1.0000 & & & 1.00 \\
11 & & & & \\
\hline
\end{tabular}

Table 5a: Vane shear strength data (kPa), (Singh, 2018)

\begin{tabular}{lllllll}
\hline Vane shear strength data $(\mathrm{kPa})$ & & & & \\
\hline 55 & 57 & 42 & 72 & 70 & 68 & 102 \\
35 & 52 & 40 & 35 & 47 & 75 & 42 \\
47 & 69 & 40 & 59 & 82 & 35 & 55 \\
39 & 68 & 62 & 72 & 69 & 42 & 32 \\
38 & 52 & 60 & 85 & 72 & 71 & \\
56 & 35 & 70 & & & \\
\hline
\end{tabular}

Table 5b: Frequencies and cumulative data for vane shear

Frequencies and cumulative data for vane shear

$\xi=\left(V_{S}=30\right) / 80 V S T=C U M / 41$

\begin{tabular}{|c|c|c|c|c|c|}
\hline $\mathrm{C} 01$ & $\mathrm{C} 02$ & $\mathrm{C} 03$ & $\mathrm{C} 04$ & $\mathrm{C} 05$ & C06 \\
\hline No. & $V_{S}$ & $\xi$ & $n$ & $C U M$ & $C S T$ \\
\hline 1 & 30 & 0.0 & 0 & 0 & 0.0 \\
\hline 2 & 40 & 0.125 & 10 & 10 & 0.2439 \\
\hline 3 & 50 & 0.250 & 7 & 17 & 0.4146 \\
\hline 4 & 60 & 0.375 & 8 & 25 & 0.6097 \\
\hline 5 & 70 & 0.500 & 7 & 32 & 0.7805 \\
\hline 6 & 80 & 0.625 & 5 & 37 & 0.9024 \\
\hline 7 & 90 & 0.750 & 2 & 39 & 0.9512 \\
\hline 8 & 100 & 0.875 & 1 & 40 & 0.9756 \\
\hline 9 & 110 & 1.00 & 1 & 41 & 1.00 \\
\hline \multicolumn{6}{|l|}{10} \\
\hline 11 & & & & & \\
\hline
\end{tabular}


Abdolrasoul Ranjbaran et al. / International Journal of Structural Glass and Advanced Materials Research 2020, Volume 4: 276.293 DOI: 10.3844/sgamrsp.2020.276.293

Table 6a: Data for cohesion factor $C^{\prime}$ (Di Matteo et al., 2013; Singh, 2018)

\begin{tabular}{|c|c|c|c|c|c|c|c|}
\hline \multicolumn{8}{|c|}{ Cohesion factor $C^{\prime}$} \\
\hline 23.56 & 21.38 & 17.75 & 22.33 & 15.73 & 21.63 & 20.18 & 24.64 \\
\hline 22.82 & 10.69 & 21.63 & 19.27 & 23.56 & 14.94 & 19.11 & 19.56 \\
\hline 18.9 & 15.02 & 20.97 & 11.23 & 21.17 & 15.52 & 24.43 & 17.00 \\
\hline 21.75 & 24.51 & 15.07 & 14.61 & 24.97 & 23.98 & 19.03 & 20.72 \\
\hline 12.05 & 27.03 & 14.20 & 22.29 & 15.27 & 13.29 & 20.76 & \\
\hline 25.05 & 19.44 & 20.80 & 23.40 & 22.45 & 27.03 & 17.91 & \\
\hline 22.29 & 16.67 & 22.82 & 16.30 & 24.31 & 19.52 & 10.12 & \\
\hline 16.51 & 10.53 & 25.96 & 17.50 & 14.28 & 23.45 & 25.05 & \\
\hline
\end{tabular}

Table 6b: Frequencies and Cumulative data for cohesion factor $C^{\prime}$

Frequencies and cumulative data for cohesion factor $C^{\prime}$

$\xi=(C P-10) / 18 C P T=C U M / 50$

\begin{tabular}{|c|c|c|c|c|c|}
\hline $\mathrm{C} 01$ & $\mathrm{C} 02$ & $\mathrm{C} 03$ & $\mathrm{C} 04$ & $\mathrm{C} 05$ & C06 \\
\hline No. & $C P$ & $\xi$ & $n$ & $C U M$ & $C P T$ \\
\hline 1 & 10 & 0.0 .00 & 0 & 0 & 0.000 \\
\hline 2 & 12 & 0.1111 & 3 & 3 & 0.066 \\
\hline 3 & 14 & 0.2222 & 3 & 6 & 0.100 \\
\hline 4 & 16 & 0.3333 & 9 & 15 & 0.250 \\
\hline 5 & 18 & 0.4444 & 11 & 26 & 0.366 \\
\hline 6 & 20 & 0.5555 & 10 & 36 & 0.483 \\
\hline 7 & 22 & 0.6666 & 8 & 44 & 0.650 \\
\hline 8 & 24 & 0.7777 & 5 & 49 & 0.833 \\
\hline 9 & 26 & 0.8888 & 1 & 50 & 0.967 \\
\hline 10 & 28 & 1.0000 & 0 & 50 & 1.000 \\
\hline 11 & & & & & \\
\hline
\end{tabular}

Table 7a: Data for shear angle $\phi^{\prime}$ (Di Matteo et al., 2013; Singh, 2018)

\begin{tabular}{llllllll}
\hline 25.99 & 26.51 & 27.51 & 25.60 & 28.09 & 25.9 & 27.50 & 25.60 \\
26.41 & 28.79 & 25.79 & 26.78 & 26.41 & 28.29 & 26.50 & 26.40 \\
27.3 & 28.53 & 26.60 & 29.61 & 26.41 & 28.00 & 25.29 & 28.21 \\
26.81 & 25.60 & 28.10 & 28.80 & 25.39 & 26.09 & 26.91 & 27.10 \\
29.6 & 25.40 & 29.00 & 25.48 & 28.61 & 28.50 & 26.69 & \\
25.08 & 28.20 & 26.89 & 26.20 & 26.81 & 25.20 & 27.30 & \\
25.48 & 26.79 & 26.41 & 27.20 & 25.39 & 26.40 & 29.30 & 25.08 \\
27.61 & 28.90 & 25.80 & 26.59 & 29.11 & 25.99 & \\
\hline
\end{tabular}

Table 7b: Frequencies and cumulative data for shear angle $\phi^{\prime}$

\begin{tabular}{|c|c|c|c|c|c|}
\hline \multicolumn{6}{|c|}{$\begin{array}{l}\text { Frequencies and cumulative data for friction angle } \phi^{\prime} \\
\xi=(P H I-25) / 4.5 P H I T=C U M / 57\end{array}$} \\
\hline $\mathrm{C} 01$ & $\mathrm{C} 02$ & $\mathrm{C} 03$ & $\mathrm{C} 04$ & $\mathrm{C} 05$ & $\mathrm{C} 06$ \\
\hline No. & PHI & $\xi$ & $n$ & $C U M$ & PHIT \\
\hline 1 & 25.0 & 0.0000 & 0 & 0 & 0.0 .00 \\
\hline 2 & 25.5 & 0.1111 & 9 & 9 & 0.1578 \\
\hline 3 & 26.0 & 0.2222 & 8 & 17 & 0.2982 \\
\hline 4 & 26.5 & 0.3333 & 9 & 26 & 0.4561 \\
\hline 5 & 27.0 & 0.4444 & 10 & 36 & 0.6316 \\
\hline 6 & 27.5 & 0.5555 & 5 & 41 & 0.7193 \\
\hline 7 & 28.0 & 0.6666 & 3 & 44 & 0.7719 \\
\hline 8 & 28.5 & 0.7777 & 6 & 50 & 0.8771 \\
\hline 9 & 29.0 & 0.8888 & 6 & 56 & 0.9824 \\
\hline 10 & 29.5 & 1.0000 & 1 & 57 & 1.000 \\
\hline 11 & & & & & \\
\hline
\end{tabular}




\section{Conclusion}

Geotechnical engineering is the art of making decisions, where the real world problems are treated and this is associated with uncertainties arising from various sources. The sources of uncertainty may be divided into uncertainties of nature (aleatory) and uncertainties of mind (epistemic). The uncertainty of nature is due to variation of encountered phenomena, e.g., the soil properties as shear strength. The uncertainties of mind are related to the modelling and may be reduced by change of philosophy. A close insight into the open literature, led the authors to detect a need for further research and remedy. Toward the aim an intensive and extensive research is conducted in the past 20+ years. The result of investigations of Author's Research Team (ART) concluded in a new perspective of the knowledge, the so called Change of State Philosophy (CSP) which is digested in the Persian Curve (PC), where a phenomenon is defined as change in the system. In the conventional methods of analysis, the system change information is indirectly obtained via solution of governing equations. Consequently, the conventional methods contain epistemic (lack of knowledge) uncertainty. On the other hand, in the (CSP) the system change information is directly obtained by logical reasoning, concise mathematics and reliable data. Consequently the (CSP) is free of epistemic uncertainty. Moreover the (CSP) is a free size method, i.e., it is independent of the size, material, coordinate system and etc. Consequently it is applicable to all natural phenomena, in different branches of human knowledge. In the presented paper the (CSP) is applied in analysis of variable data in geotechnical engineering. Via application of the (PC) to seven set of reliable data the validity of the work is verified.

\section{Acknowledgement}

Thanks to all members of our family, specially Zahra, who provided a calm state and condition, at the time of Corona at home and encouraged writing of the paper.

\section{Author's Contributions}

All authors equally contributed in this study.

\section{Ethics}

This article is original and contains unpublished material. The corresponding author confirms that all of the other authors have read and approved the manuscript and no ethical issues involved with declaration of no conflict of interest.

\section{Appendix}

\section{Determination of Control Parameters}

Close insight into Equation (13) and Equation (19) concluded into the selection of the middle point $(M)$ as an important key point due to the property in Equation (38):

$D_{M}=0.5 O_{M}=0.5 D_{M}=O_{M}$

Substitution of Equation (38) into Equation (19) concluded into a simple definition for the $\left(a_{M}\right)$ in Equation (39):

$$
P_{M}=\frac{P_{O} O_{M}^{b}+P_{T} a_{M} D_{M}^{b}}{O_{M}^{b}+a_{M} D_{M}^{b}} \Rightarrow a_{M}=\frac{P_{M}-P_{O}}{P_{T}-P_{M}}
$$

Moreover the control parameter $(b)$ is determined by substitution of Equation (39) and coordinates of the next key point $(N)$ into Equation (19), as in Equation (40):

$$
\begin{aligned}
& P_{N}=\frac{P_{O} O_{N}^{b}+P_{T} a_{M} D_{N}^{b}}{O_{N}^{b}+a_{M} D_{N}^{b}} \Rightarrow\left(\frac{D_{N}}{O_{N}}\right)^{b}=\frac{P_{N}-P_{O}}{\left(P_{T}-P_{N}\right) a_{M}} \\
& a_{N}=\frac{P_{N}-P_{O}}{P_{T}-P_{N}} \Rightarrow b=\frac{\log \left(a_{N} / a_{M}\right)}{\log \left(D_{N} / O_{N}\right)}
\end{aligned}
$$

Since the direction of ( $T$ to $C$ ) and ( $C$ to $O$ ), for a point $(C)$ on both of the increasing and decreasing data, is the same, then the control parameters $\left(a_{M}\right.$ and $\left.b\right)$ are always positive.

\section{References}

Aladejare, A. E., \& Wang, Y. (2018). Influence of rock property correlation on reliability analysis of rock slope stability: from property characterization to reliability analysis. Geoscience Frontiers, 9(6), 1639-1648.

Allahverdizadeh Sheykhloo, P. (2015). Risk assessment and spatial variability in geotechnical stability problems (Doctoral dissertation, Colorado School of Mines. Arthur Lakes Library).

Amirian, P., \& Ranjbaran, A. (2020). Studying the Effect of Fundamental Structural Period on the Seismic Fragility Curves of Two-Span Integral Concrete Box Girder Bridges. Iranian Journal of Science and Technology, Transactions of Civil Engineering, 44(1), 11-26.

Anderson, T. L. (2005). Fracture mechanics: fundamentals and applications. CRC Press, Taylor and Francis Group, LLC, USA, 2005.

Ang, A. H. S., \& Tang, W. H. (2007). Probability concepts in engineering planning and design: Emphasis on application to civil and environmental engineering. Wiley. 
Baharvand, A., \& Ranjbaran, A. (2020a). Seismic Fragility Functions Grounded on State-Based Philosophy: Application to Low to Midrise Steel Frame Buildings. KSCE Journal of Civil Engineering, 1-12.

Baharvand, A., \& Ranjbaran, A. (2020b). A new method for developing seismic collapse fragility curves grounded on state-based philosophy. International Journal of Steel Structures, 1-17.

Baker, R. (1990). Probability estimation and information principles. Structural safety, 9(2), 97-116.

Cao, Z., \& Wang, Y. (2013). Bayesian approach for probabilistic site characterization using cone penetration tests. Journal of Geotechnical and Geoenvironmental Engineering, 139(2), 267-276.

Ching, J., Phoon, K. K., \& Chen, Y. C. (2010). Reducing shear strength uncertainties in clays by multivariate correlations. Canadian Geotechnical Journal, 47(1), 16-33.

Christian, J. T. (2004). Geotechnical engineering reliability: How well do we know what we are doing?. Journal of geotechnical and geoenvironmental engineering, 130(10), 985-1003.

Cui, J., Jiang, Q., Li, S., Feng, X., Zhang, M., \& Yang, B. (2017). Estimation of the number of specimens required for acquiring reliable rock mechanical parameters in laboratory uniaxial compression tests. Engineering Geology, 222, 186-200.

Das, R. (2016). Probabilistic Slope Stability Assessment of Submarine and Slides by the Use of Bayesian Inference (Doctoral dissertation).

Deng, J., Li, X. B., \& Gu, G. S. (2004). A distributionfree method using maximum entropy and moments for estimating probability curves of rock variables. International Journal of Rock Mechanics and Mining Sciences, 41, 127-132.

Di Matteo, L., Valigi, D., \& Ricco, R. (2013). Laboratory shear strength parameters of cohesive soils: variability and potential effects on slope stability. Bulletin of Engineering Geology and the Environment, 72(1), 101-106.

El-Ramly, H., Morgenstern, N. R., \& Cruden, D. M. (2002). Probabilistic slope stability analysis for practice. Canadian Geotechnical Journal, 39(3), 665-683.

Ersöz, T. (2017). Slope stability assessment of various road cuts with effects of weathering at North West Black Sea Region (Turkey) (Master's thesis, Master's thesis), Middle East Technical University, Ankara, Turkey).

Griffiths, D. V., \& Fenton, G. A. (2004). Probabilistic slope stability analysis by finite elements. Journal of geotechnical and geoenvironmental engineering, 130(5), 507-518.
Hernvall, H. (2017). Clay slopes and their stability: An evaluation of different methods (Master's thesis).

Johari, A., \& Khodaparast, A. R. (2015). Analytical stochastic analysis of seismic stability of infinite slope. Soil Dynamics and Earthquake Engineering, 79, 17-21.

Johari, A., \& Mousavi, S. (2019). An analytical probabilistic analysis of slopes based on limit equilibrium methods. Bulletin of Engineering Geology and the Environment, 78(6), 4333-4347.

Johari, A., Hajivand, A. K., \& Binesh, S. M. (2020). System reliability analysis of soil nail wall using random finite element method. Bulletin of Engineering Geology and the Environment, 1-22.

Johari, A., Mousavi, S., \& Hooshmand Nejad, A. (2015). A seismic slope stability probabilistic model based on Bishop's method using analytical approach. Scientia Iranica, 22(3), 728-741.

Kanwar, N. S. (2018). Entropy-based reliability analysis and design in slope engineering (Doctoral dissertation).

Li, L. (2014). Reliability based design for slope stabilization using drilled shafts and anchors (Doctoral dissertation, University of Akron).

Lumb, P. (1974). Application of statistics in soil mechanics. Soil Mechanics New Horizons. IK Lee, ed.

Maknoon, M. (2016). Slope stability analyses of waste rock piles under unsaturated conditions following large precipitations. PhD Dissertation, Department of Civil, Geology and Mines, University of Montreal, Canada.

Masoudian, M. S., Afrapoli, M. A. H., Tasalloti, A., \& Marshall, A. M. (2019). A general framework for coupled hydro-mechanical modelling of rainfallinduced instability in unsaturated slopes with multivariate random fields. Computers and Geotechnics, 115, 103162.

Müller, R. (2013). Probabilistic stability analysis of embankments founded on clay (Doctoral dissertation, KTH Royal Institute of Technology).

Obregon, C., \& Mitri, H. (2019). Probabilistic approach for open pit bench slope stability analysis-A mine case study. International Journal of Mining Science and Technology, 29(4), 629-640.

Orchant, C. J. (1987). Critical evaluation of in-situ test methods and their variability. Cornell University, USA.

Peck, R. B. (1969). Advantages and limitations of the observational method in applied soil mechanics. Geotechnique, 19(2), 171-187.

Phoon, K. K., \& Kulhawy F. H. (1999). Evaluation of geotechnical property variability. Canadian Geotechnical Journal; 36(4): 625-639.

Ranjbaran, A. (2010). Analysis of cracked members the governing equations and exact solutions. 
Ranjbaran, A. (2012a). Analysis of cracked members: free vibration, buckling, dynamic stability. Lap Lambert Academic Publishing Saarbrucken Germany.

Ranjbaran, A. (2012b). The dynamic stability analysis application to beam like structures. Lap Lambert Academic Publishing. ISBN: 987-3-659-23467-5.

Ranjbaran, A. (2013). The finite element method for research: interesting and innovative ideas. Lap Lambert Academic Publishing Saarbrucken Germany.

Ranjbaran, A. (2014). Free-vibration analysis of stiffened frames. Journal of Engineering Mechanics, 140(9), 04014071.

Ranjbaran, A. (2015). Buckling analysis of stiffened frames. Ned University Journal of Research, 12(1).

Ranjbaran, A. (2016). New generalised weight function for stress intensity factor. Ned University Journal of Research, 13(1), 33-42.

Ranjbaran, A., \& Ranjbaran, M. (2014). New finiteelement formulation for buckling analysis of cracked structures. Journal of Engineering Mechanics, 140(5), 04014014.

Ranjbaran, A., \& Ranjbaran, M. (2016). State functions: the milestone of fracture. Archive of Applied Mechanics, 86(7), 1311-1324.

Ranjbaran, A., \& Ranjbaran, M. (2017a). State-based buckling analysis of beam-like structures. Archive of Applied Mechanics, 87(9), 1555-1565.

Ranjbaran, A., \& Ranjbaran, M. (2017b). State based damage mechanics. NED University Journal of Research, 14(1), 13-26.

Ranjbaran, A., \& Ranjbaran, M. (2017c). Innovative theory for the compliance computation in rotors. Scientia Iranica, 24(4), 1779-1788.

Ranjbaran, A., \& Ranjbaran, M. (2018). State based method for ultimate strength analysis of stiffened panels. Ned University Journal of Research, 15(1).

Ranjbaran, A., \& Rousta, H. (2013a). Interaction diagram for dynamic stability by Laplace transform. NED University Journal of Research, 10(1), 31-39.

Ranjbaran, A., \& Rousta, H. (2013b). Finite element analysis of cracked beams innovative weak form equations. NED University Journal of Research, $10(1), 39-47$.

Ranjbaran, A., Hashemi, S., \& Ghafarian, A. (2008). A new approach for buckling and vibration analysis of cracked column.

Ranjbaran, A., Ranjbaran, M., \& Baharvand, A. (2020a). A step toward development of generic fragility curves. Ned University Journal of Research, 17(3).

Ranjbaran, A., Ranjbaran, M., \& Ranjbaran, F. (2020b). Change of state philosophy \& Persian curves. LAP LAMBERT Academic Publishing, 225.

Ranjbaran, A., Ranjbaran M., \& Ranjbaran F. (2020c). Building probability functions by Persian curves. International Journal of Structural Glass and Advanced Materials Research, 2020; 4(1): 225-232.
Ranjbaran, A., Ranjbaran, M., \& Ranjbaran, F. (2020d). A reliable fracture mechanics. International Journal of Reliability, Risk and Safety: Theory and Application; 2020; 3(1): 1-15.

Ranjbaran, A., Rousta, H., \& Ranjbaran, M. (2013a). Dynamic stability of cracked columns; the stiffness reduction method. Scientia Iranica, 20(1), 57-64.

Ranjbaran, A., Rousta, H., Ranjbaran, M. O., Ranjbaran, M. A., Hashemi, M., \& Moravej, M. T. (2013b). A necessary modification for the finite element analysis of cracked members detection, construction and justification. Archive of Applied Mechanics, 83(7), 1087-1096.

Ranjbaran, A., Shokrzadeh, A. R., \& Khosravi, S. (2011). A new finite element analysis of free axial vibration of cracked bars. International Journal for Numerical Methods in Biomedical Engineering, 27(10), 1611-1621.

Singh, S. (2018). Quantile-based reliability analysis and design in slope stability (Doctoral dissertation).

Tran, Q. A. (2019). Material Point Method: algorithm development and application to landslide modelling.

Wolebo, A. P. (2016). Advanced probabilistic slope stability analysis on Rissa Slope (Master's thesis, NTNU).

Wu, T. H. (2011). 2008 Peck lecture: the observational method: case history and models. Journal of geotechnical and geoenvironmental engineering, 137(10), 862-873.

$\mathrm{Xu}$, B., \& Low, B. K. (2006). Probabilistic stability analyses of embankments based on finite-element method. Journal of Geotechnical and Geoenvironmental Engineering, 132(11), 1444-1454.

Zhang, J., Tang, W. H., \& Zhang, L. M. (2010). Efficient probabilistic back-analysis of slope stability model parameters. Journal of Geotechnical and Geoenvironmental Engineering, 136(1), 99-109.

Zhang, J., Zhang, L. M., \& Tang, W. H. (2009). Bayesian framework for characterizing geotechnical model uncertainty. Journal of Geotechnical and Geoenvironmental Engineering, 135(7), 932-940.

Zhang, L., Tang, W. H., Zhang, L., \& Zheng, J. (2004). Reducing uncertainty of prediction from empirical correlations. Journal of Geotechnical and Geoenvironmental Engineering, 130(5), 526-534.

\section{List of Symbols}

$\begin{array}{ll}a_{M}: & \text { Control parameter at } M \\ a_{N}: & \text { Control parameter at } N \\ A_{ \pm}: & \text {Sign parameter } \\ A_{ \pm}=-1: & \text { For decreasing data } \\ A_{ \pm}=+1: & \text { For increasing data } \\ b: & \text { Control parameter (power) } \\ C S P: & \text { Change of state philosophy }\end{array}$


$D$ :

$E$ :

$F_{y}:$

$f_{s}:$

$f_{C}$ :

$F_{S}$ :

$f_{S F}:$

$F_{R}$ :

$\left(F_{R}\right.$ and $\left.S_{R}\right)$ :

$f_{W}$ :

$F_{W}:$

$\gamma$.

$k_{s}$ :

$k_{C}$ :

$k_{S S}:$

$K P F$ :

$K P S$ :

KPS:

$L:$

$L B$ :

$\lambda$ :

$\lambda=\frac{L}{r} \sqrt{\frac{F_{y}}{\pi^{2} E}}:$

$\lambda_{o}$ :
Destination function

Initial modulus

Yield limit

System flexibility

Change flexibility

Dimensioned flexibility

Survived flexibility

Failure function

Phenomenon functions

Weibull probability density function

Weibull cumulative distribution function

Recovery rate

System stiffness

Change stiffness

Survived stiffness

Key points on failure curve

Key points on survive curve

Key points

Effective length

Lower bound

Lifetime parameter

Relative slenderness ratio

Lifetime origin
$\lambda_{T}:$

$M:$

$N:$

$O:$

$O:$

$P C$ :

$P_{O}$ :

$P_{N}:$

$P_{M}:$

$P_{T}:$

$P_{F U}:$

$P_{S U}:$

$P_{Z U}:$

$P_{Z}:$

$P_{F}:$

$P_{S}:$

$P_{C}=\left(P_{F}\right.$ and $\left.P_{S}\right)$ : Persian curves

$r: \quad$ Effective radius of gyration

$R: \quad$ State ratio

$S_{R}: \quad$ Survive function

$S_{F}=(D$ and $O): \quad$ State functions

$T:$

$U B$ :

$\xi$
Termination (end) point

Lifetime termination (end)

Next po

Origin (start) point

Origin function

Origin point ordinate

Next point ordinate

Middle point ordinate

End point ordinate

Unified Persian-failure function

Persian-distribution function

Persian-failure function

Persian-survive function

Upper bound

State variable 